\title{
High-Energy-Density Materials: An Amphoteric N-Rich Bis(triazole) and Salts of Its Cationic and Anionic Species
}

Emmanuele Parisi, Alessandro Landi, Sandra Fusco, Carla Manfredi, Andrea Peluso, Sabrina Wahler, Thomas M. Klapötke, and Roberto Centore*

Cite This: Inorg. Chem. 2021, 60, 16213-16222

Read Online

ABSTRACT: The synthesis and characterization of the N-rich bis(triazole) compound $1 H, 4^{\prime} H$-[3,3'-bis(1,2,4-triazole) $]-4^{\prime}, 5,5^{\prime}$-triamine $\left(\mathrm{C}_{4} \mathrm{H}_{7} \mathrm{~N}_{9}\right)$ with a $\mathrm{N}$ content of $69.6 \%$ by weight is reported. The compound exhibits a rich acid-base behavior because it can accept up to two protons, forming a monocation and a dication, and can lose one proton, forming an anion. Measurement of the acid constants has shown that there exist well-defined $\mathrm{pH}$ intervals in which each of the four species is predominant in solution, opening the way to their isolation and characterization by single-crystal X-ray analysis as salts with different counterions. Some energetic salts of the monocation or dication containing oxidizing inorganic counterions (dinitramide, perchlorate, and nitrate) were also prepared and characterized in the solid state for their sensitivity. In particular, the neutral compound shows a very

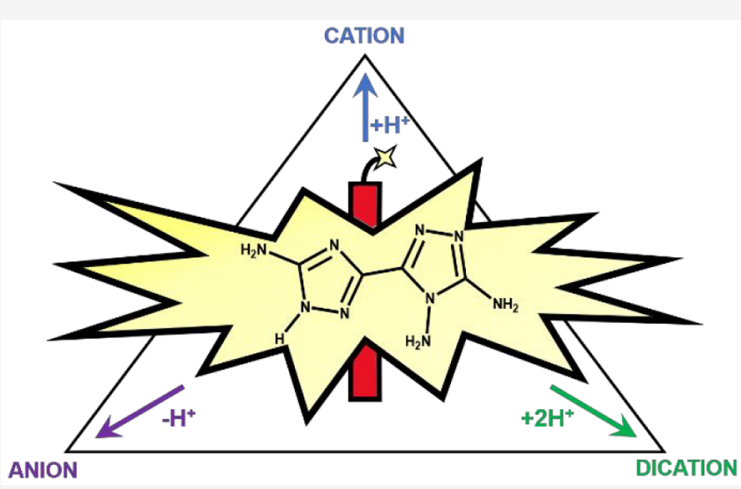
remarkable thermal stability in air, with $T_{\mathrm{d}}=347{ }^{\circ} \mathrm{C}$, and is insensitive to impact and friction. Salts of the dication with energetic counterions, in particular perchlorate and nitrate, show increased sensitivities and reduced thermal stability. The salt of the monocation with dinitramide as the counterion outperforms other dinitramide salts reported in the literature because of its higher thermal stability $\left(T_{\mathrm{d}}=230{ }^{\circ} \mathrm{C}\right.$ in air $)$ and friction insensitiveness.

\section{INTRODUCTION}

High-energy-density materials (HEDMs) can store and release in a controllable manner a high amount of (chemical) energy; thus, they are widely exploited in military and civil areas. ${ }^{1}$ When undergoing decomposition, energetic materials produce energy by oxidation processes. One basic problem with HEDMs is that compounds highly performing from the energetic side are often sensitive to external stimuli such as heat, impact, friction, and detonation, requiring some sort of stabilization to control the energy release and avoid accidents. Recently, various classes of heterocyclic compounds with high $\mathrm{N}$ content have attracted considerable interest for the development of HEDMs as an alternative to traditional materials because of their excellent stability, high heat of formation, and environmentally friendly conditions. ${ }^{2}$ The average bond energy of the $\mathrm{N}-\mathrm{N}$ triple bond $(954 \mathrm{~kJ} / \mathrm{mol}$ ) is very high, which makes $\mathrm{N}$-rich compounds very endothermic and, therefore, very energetic materials. Also, N-rich heterocycles generally contain $\mathrm{N}$ in negative oxidation states, and these materials can decompose, giving environmentally benign gases (i.e., mainly $\mathrm{N}_{2}$ ). Another advantage of N-rich heterocycles is the presence of basic $\mathrm{N}$ atoms or acidic $\mathrm{N}-\mathrm{H}$ groups, which can lead to the formation of coordination compounds or salts in which the N-rich heterocycle is present as a cation or an anion. These salts have intrinsically low volatility and an increased energy content coming from the high energy of the ionic lattice, and their properties can be tuned, in principle, by the appropriate choice of the counterion and by crystal engineering strategies.

Here we report on the synthesis and characterization of HEDMs based on the N-rich heterocyclic compound $1 \mathrm{H}, 4^{\prime} \mathrm{H}$ [3,3'-bis(1,2,4-triazole)]-4',5,5'-triamine (henceforth compound 1) shown in Chart 1 . It belongs to the class of 1,2,4triazoles, which have been widely explored in recent years, ${ }^{3-9}$ and has a high $\mathrm{N}$ content $(69.6 \%)$.

The electron-rich character of $\mathbf{1}$, which contains three amino electron-donor groups, is compatible with a rich acid-base behavior. In principle, $\mathbf{1}$ can take up to two protons, forming a cation and a dication, while the acidic $\mathrm{N}-\mathrm{H} \mathrm{H}$ atom can be lost by reaction with bases, with formation of the anion (Chart 1). So, at variance with most of the energetic N-rich compounds studied so far, with $\mathbf{1}$, it is possible, in principle, to prepare salts in which the $\mathrm{N}$-rich heterocycle is present as a

Received: July 2, 2021

Published: October 12, 2021 
Chart 1. Neutral, Singly Protonated, Doubly Protonated, and Deprotonated Forms of $1^{a}$

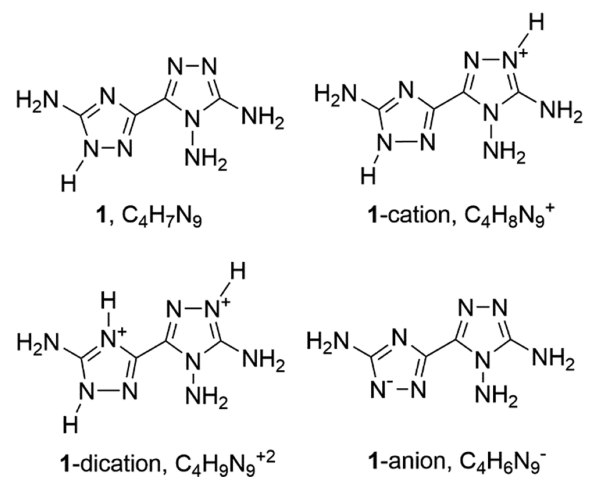

${ }^{a}$ Only one tautomeric form is shown for the neutral and cationic species. For the anion, only one resonance form is shown.

cation/dication and salts in which it is present as an anion. Indeed, those salts have been prepared and will be described in the present paper, with full characterization of their properties in the solution and solid state, including measurements of the sensitivities in the solid state for the energetic compounds. Some energetic salts of the $\mathbf{1}$ dication (nitrate and perchlorate) have recently been studied, independently from us, by the groups of Shreeve ${ }^{10}$ and Cheng/Yang, ${ }^{11}$ with possible application as gas-generating agents, propellants, or explosives. We note that a compound similar to 1 but containing one fewer $\mathrm{NH}_{2}$ group (\% N 67.4) was used by Shreeve in 2010, ${ }^{12}$ while another one containing one more $\mathrm{NH}_{2}$ group (\% $\mathrm{N}$ 71.4) was described by us. ${ }^{3,5,6}$

\section{RESULTS AND DISCUSSION}

Tautomerism. Tautomerism is a phenomenon common to several classes of $\mathrm{N}$-containing aromatic heterocycles, exhibiting many intriguing aspects that are relevant in many areas, including crystal engineering, ${ }^{13}$ drug design, ${ }^{14}$ energetic materials, $^{15}$ and coordination chemistry. ${ }^{16,17}$ Of particular interest are compounds for which quasi-degenerate tautomers are possible because they can be switched between each other depending on the environment. ${ }^{18,19}$ The N-rich system of $\mathbf{1}$ is potentially tautomeric. In Chart 2 are reported the canonical tautomers of the neutral and singly protonated species. Moreover, two different conformers can be expected for each tautomer, differing by the relative orientation of the triazole rings, which can be s-trans or s-cis if we look at the bond between the two rings.

The computed relative energies of the tautomers/conformers of Chart 2 are shown in Table 1. For the neutral molecule, the most stable predicted species, in a polar medium, is $1 \mathrm{H} / \mathrm{s}$-trans. The $2 \mathrm{H}$ tautomer, however, follows quite closely in energy both in the s-trans and, mostly, in the s-cis conformation. In the gas phase, $2 \mathrm{H} / \mathrm{s}$-cis is predicted as the most stable species, probably as a result of an intramolecular $\mathrm{N}-\mathrm{H} \cdots \mathrm{N}$ interaction, and in a polar medium, the energy of $2 \mathrm{H} / \mathrm{s}$-cis is only $0.5 \mathrm{kcal} / \mathrm{mol}$ higher than $1 \mathrm{H} / \mathrm{s}$-trans, a value that is within the accuracy of the method used in the calculations. On the other hand, the $4 H$ conformer has significantly higher energy.

Concerning singly protonated species, the data of Table 1 indicate that the tautomer $1 H-1^{\prime} H$ is the most stable both in the gas phase and in a polar medium. The other tautomers all
Chart 2. Some Possible Tautomers of 1 and of Its Singly Protonated Cation (Only s-trans Conformers Are Shown) ${ }^{a}$<smiles>Nc1nnc(-c2nc(-n3nc(-c4nnc(N)n4N)nc3N)c(N)n2N)[nH]1</smiles>

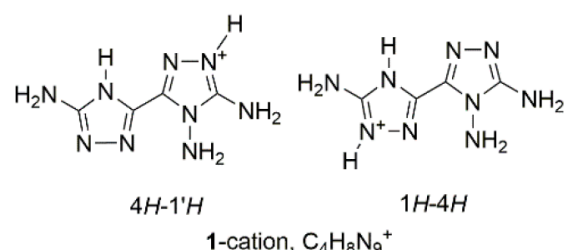

${ }^{a}$ Highlighted in red are the tautomers/conformers predicted as the most stable by computational analysis.

Table 1. Computed Relative Energies ( $\mathrm{kcal} / \mathrm{mol}$ ) of Tautomers/Conformers of Neutral and Singly Protonated 1

\begin{tabular}{lccccc} 
& \multicolumn{2}{c}{ gas } & & \multicolumn{2}{c}{ water } \\
\cline { 2 - 3 } \cline { 5 - 6 } tautomer & s-cis & s-trans & & s-cis & s-trans \\
$1 H$ & 6.7 & 6.3 & & 0.4 & 0.0 \\
$2 H$ & 0.0 & 9.2 & & 0.5 & 1.3 \\
$4 H$ & 18.2 & 6.4 & & 5.2 & 3.5 \\
$1 H-1^{\prime} H$ & 0.4 & 0.0 & & 0.5 & 0.0 \\
$2 H-1^{\prime} H$ & 3.6 & not stable ${ }^{a}$ & & 3.0 & 7.1 \\
$4 H-1^{\prime} H$ & 23.2 & 7.2 & & 7.6 & 5.0 \\
$1 H-4 H$ & 18.2 & 13.8 & & 6.1 & 7.8
\end{tabular}

${ }^{a}$ Interconverts in the conformer s-cis upon geometry optimization.

have significantly higher energy. For the doubly protonated cation, we have not performed any computation. In fact, the tautomer shown in Chart 1 is only possible when both positive charges are on the $\mathrm{N}$ atoms adjacent to the $\mathrm{C}-\mathrm{NH}_{2}$ groups.

Acid-Base Equilibria in Solution. The acid-base equilibria of 1 in solution have been studied at $25{ }^{\circ} \mathrm{C}$ by potentiometric-spectrophotometric titrations in the constant ionic medium $0.5 \mathrm{M} \mathrm{NaCl}$ (see also the Supporting Information, SI). UV-vis absorption spectra of 1 recorded at different $\mathrm{pH}$ values and a constant total concentration are reported in Figure 1.

There is a nonmonotonic dependence of $\lambda_{\max }$ from the $\mathrm{pH}$. Starting from the lowest value of the $\mathrm{pH}\left(\mathrm{pH}=0.7, \lambda_{\max }=257\right.$ $\mathrm{nm})$, there is an initial hypsochromic shift up to $\mathrm{pH}=2.9\left(\lambda_{\max }\right.$ $=248 \mathrm{~nm})$. Then, with increasing $\mathrm{pH}$, the shift of $\lambda_{\max }$ is always bathochromic up to $\mathrm{pH}=6.6\left(\lambda_{\max }=257 \mathrm{~nm}\right)$ and further on to $\mathrm{pH}=9.8\left(\lambda_{\max }=264 \mathrm{~nm}\right)$. The changes in the absorption spectra can be accounted for by the three equilibria of Table 2 (see also the SI): neutral 1 (HL) can accept up to two protons, forming the cationic species $\mathrm{H}_{2} \mathrm{~L}^{+}$and $\mathrm{H}_{3} \mathrm{~L}^{2+}$, and can release one proton, forming the species $\mathrm{L}^{-}$.

The distribution diagram of the species is reported in Figure 2. It is noteworthy that there exist definite $\mathrm{pH}$ intervals in which each of the four species involved in the protolytic 


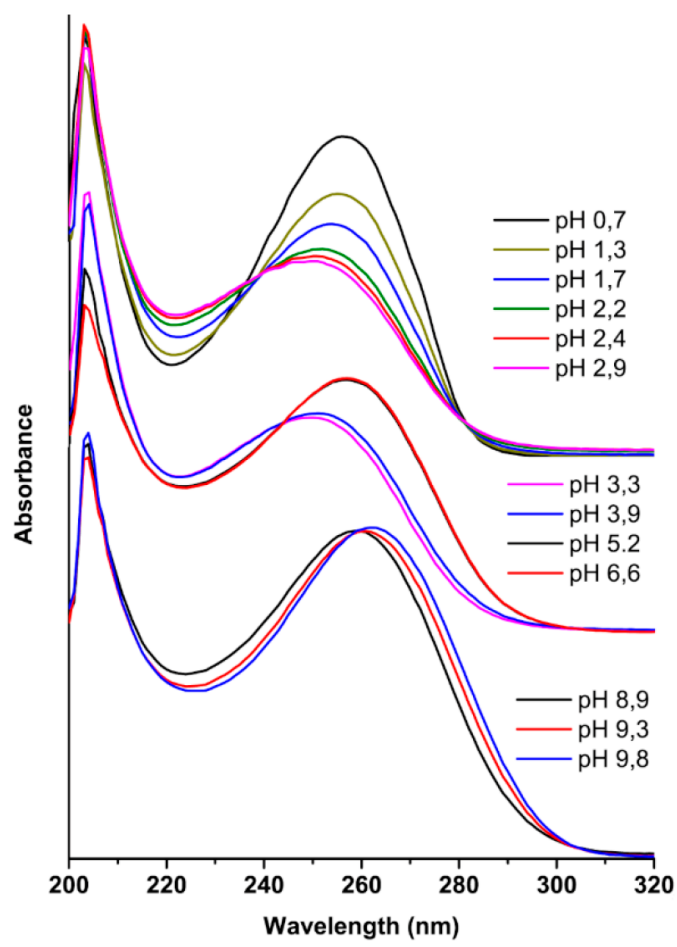

Figure 1. UV-vis absorption spectra of 1 at constant total concentration $c=5.01 \times 10^{-5} \mathrm{M}$ in $0.5 \mathrm{M} \mathrm{NaCl}$ recorded at $0.7 \leq$ $\mathrm{pH} \leq 9.8$. The spectra have been grouped into three sets of curves arbitrarily shifted along the vertical axis for easier lecture. The three sets correspond to the three equilibria involved (vide ultra and the SI).

Table 2. Acid Constants in the Form of $\mathrm{pK}_{\mathrm{a}}$ (at $25^{\circ} \mathrm{C}$ in 0.5 $\mathrm{M} \mathrm{NaCl}$, with Estimated Standard Deviations in Parentheses) for 1 (HL)

\begin{tabular}{lc}
\multicolumn{1}{c}{ equilibrium } & $\mathrm{p} K_{\mathrm{a}}$ \\
$\mathrm{H}_{3} \mathrm{~L}^{2+}+\mathrm{H}_{2} \mathrm{O}=\mathrm{H}_{3} \mathrm{O}^{+}+\mathrm{H}_{2} \mathrm{~L}^{+}$ & $\mathrm{p} K_{\mathrm{a} 1}=1.31(2)$ \\
$\mathrm{H}_{2} \mathrm{~L}^{+}+\mathrm{H}_{2} \mathrm{O}=\mathrm{H}_{3} \mathrm{O}^{+}+\mathrm{HL}$ & $\mathrm{p} K_{\mathrm{a} 2}=4.56(2)$ \\
$\mathrm{HL}+\mathrm{H}_{2} \mathrm{O}=\mathrm{H}_{3} \mathrm{O}^{+}+\mathrm{L}^{-}$ & $\mathrm{p} K_{\mathrm{a} 3}=9.25(5)$ \\
\hline
\end{tabular}

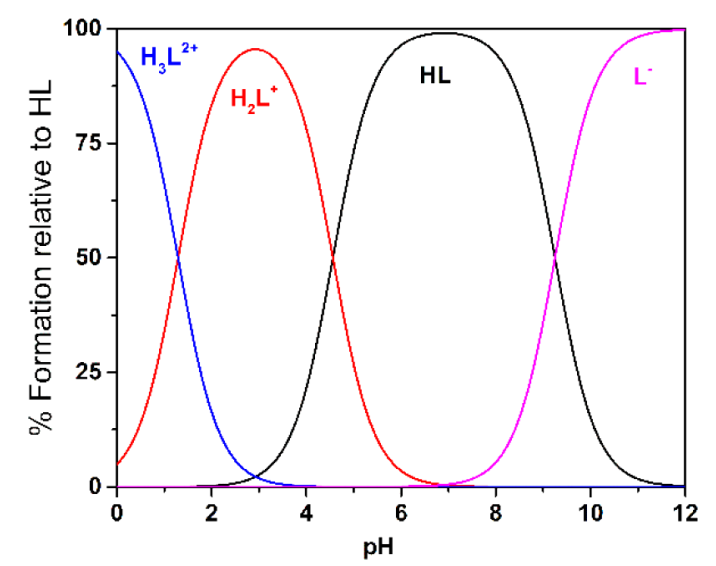

Figure 2. Distribution diagram of $\mathbf{1}(\mathrm{HL})$, calculated using the constants of Table 2.

equilibria is present in solution at a molar fraction of $\geq 90 \%$. This should allow salts containing each of the three ionic species of 1 to be isolated from solutions.

Structural and Solid-State Analysis of 1 and Its Salts. We successfully crystallized neutral 1, 1 monocation as the dinitramide salt, $\left(\mathrm{C}_{4} \mathrm{H}_{8} \mathrm{~N}_{9}\right)\left(\mathrm{N}_{3} \mathrm{O}_{4}\right), 1$ dication as bromide, perchlorate, nitrate, and tetrachlorozincate salts, $\left(\mathrm{C}_{4} \mathrm{H}_{9} \mathrm{~N}_{9}\right) \mathrm{Br}_{2}$, $\left(\mathrm{C}_{4} \mathrm{H}_{9} \mathrm{~N}_{9}\right)\left(\mathrm{ClO}_{4}\right)_{2},\left(\mathrm{C}_{4} \mathrm{H}_{9} \mathrm{~N}_{9}\right)\left(\mathrm{NO}_{3}\right)_{2}$, and $\left(\mathrm{C}_{4} \mathrm{H}_{9} \mathrm{~N}_{9}\right)\left(\mathrm{ZnCl}_{4}\right)$, respectively, and 1 anion as the potassium salt, $\mathrm{K}\left(\mathrm{C}_{4} \mathrm{H}_{6} \mathrm{~N}_{9}\right)$ (Chart 3).

Chart 3. Composition and Numbering of Salts of 1

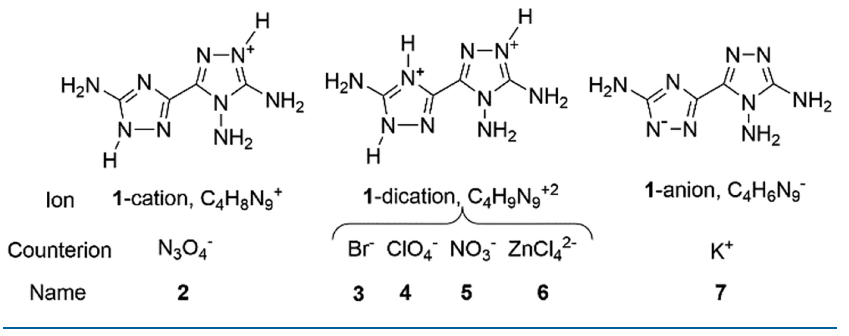

For these compounds, single-crystal X-ray diffraction analysis was performed. Remarkably, the molecular structures of all of the species involved in the acid-base equilibria have been characterized. As a general remark, we note that neutral 1 and its singly and doubly protonated species (Chart 1) are characterized by the presence of several strong H-bonding donor and acceptors on the rim of the molecule. Most of these groups, for instance, the ring $\mathrm{N}$ atoms and the $\mathrm{C}-\mathrm{NH}_{2}$ or $\mathrm{N}^{+}-\mathrm{H}$ groups, are strong in-plane $\mathrm{H}$-bonding acceptors/donors. So, a tendency toward the formation of stacked structures, in which infinite planar layers of $\mathrm{H}$-bonded molecules are piled on each other, is expected for these compounds.

Neutral 1 has been crystallized as a hemihydrate, $\mathrm{C}_{4} \mathrm{H}_{7} \mathrm{~N}_{9}$. $0.5 \mathrm{H}_{2} \mathrm{O}$. Crystals are triclinic $P \overline{1}$ with $Z=8$. The crystallographic analysis unambiguously indicates that the tautomer present in the crystals is $1 H$ (Figure 3a). The four crystallographically independent molecules, all in the s-trans $1 \mathrm{H}$ tautomer, have a basically flat conformation, with the dihedral angle between the average planes of the two pentatomic rings ranging between $4.2(1)^{\circ}$ for molecule A and $11.8(1)^{\circ}$ for molecule $\mathrm{D}$. The bond geometry around amino $\mathrm{N}$ atoms is relevant for the packing because they are $\mathrm{H}$ bonding donors. The geometry is pyramidal for (N)- $\mathrm{NH}_{2}$ atoms [the sum of the valence angles around the amino $\mathrm{N}$ atom ranges between $320(3)^{\circ}$ and $327(2)^{\circ}$ for the four independent molecules]. This result basically remains unchanged in all of the structures studied (vide ultra). The geometry around the (C) $-\mathrm{NH}_{2} \mathrm{~N}$ atoms is still pyramidal, but more flat, because of conjugation with the aromatic ring, with the sum of the valence angles around the amino $\mathrm{N}$ atom ranging, in this case, between $341(2)^{\circ}$ and $358(3)^{\circ}$ for the four independent molecules.

Molecules in the crystal form infinite planar layers through $\mathrm{H}$ bonds involving the many $\mathrm{N}-\mathrm{H}$ donor and $\mathrm{N}$ acceptors present in the molecules of $\mathbf{1}$ and the water molecules (Figure $3 \mathrm{~b}, \mathrm{c})$. The layers are parallel to the lattice plane $2 \overline{1} 0$, and, in fact, reflection $2 \overline{1} 0$ is the most intense of the whole diffraction pattern. The stacking of the layers is achieved through $\mathrm{H}$ bonds between adjacent layers, and the stacking distance of the planes is rather short, $d_{2 \overline{1} 0}=3.12 \AA$. The extended network of strong $\mathrm{H}$ bonds accounts for the relatively high density of the crystal, which is $1.629 \mathrm{~g} / \mathrm{cm}^{3}$ at $-100{ }^{\circ} \mathrm{C}$.

By metathesis of the perchlorate salt, $\left(\mathrm{C}_{4} \mathrm{H}_{9} \mathrm{~N}_{9}\right)\left(\mathrm{ClO}_{4}\right)_{2}$, with potassium dinitramide $\left(\mathrm{KN}_{3} \mathrm{O}_{4}\right)$, we have obtained the dinitramide salt of monoprotonated 1, i.e., compound 2 of Chart 3. The crystal structure is shown in Figure 4. 


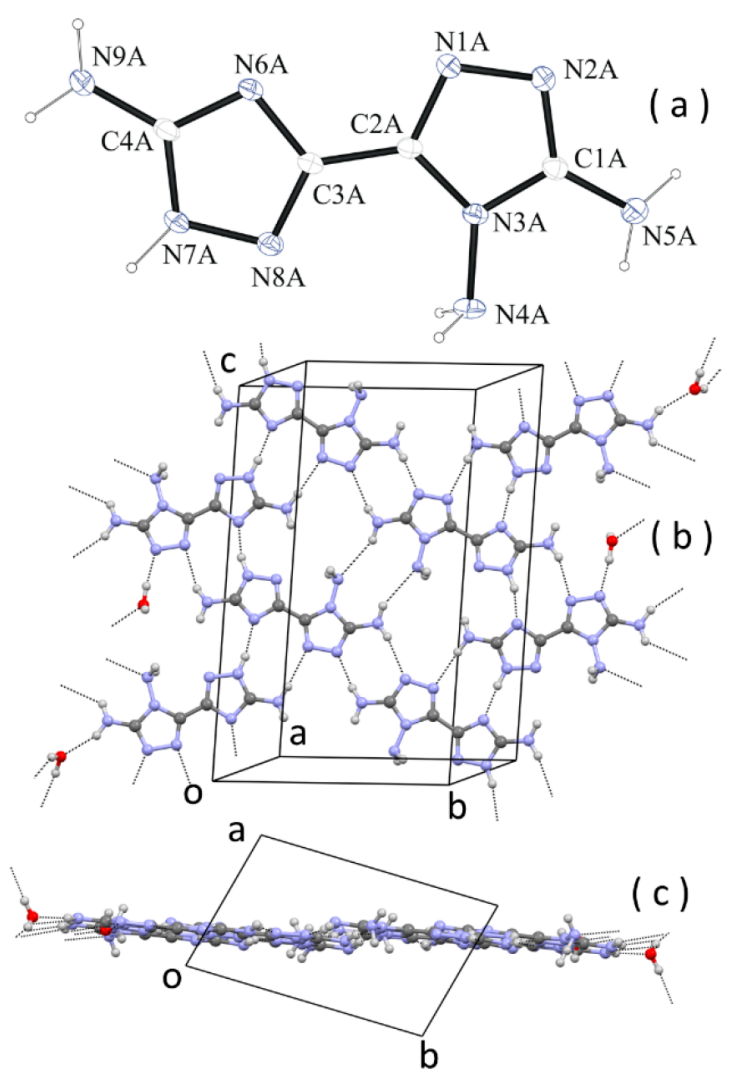

Figure 3. (a) ORTEP diagram of one of the four crystallographically independent molecules of $\mathrm{C}_{4} \mathrm{H}_{7} \mathrm{~N}_{9} \cdot 0.5 \mathrm{H}_{2} \mathrm{O}$. (b) Face view of a layer of H-bonded molecules. (c) Same layer viewed along c. Some $\mathrm{H}$ bonds are indicated by dashed lines.

The cation is present as the $1 H-1^{\prime} H$ tautomer (Figure $4 a$ ), consistent with the results of computational analysis, so single protonation of $\mathbf{1}$ is observed at the triazole ring bearing two amino groups. The conformation of the cation is basically flat, with the dihedral angle between the average planes of the two rings being $5.2(2)^{\circ}$. The geometry around the amino $(\mathrm{N})-\mathrm{NH}_{2}$ atom is pyramidal [the sum of the valence angles is $319(4)^{\circ}$ ]. Compared with neutral $\mathbf{1}$, full planarization of the geometry around the (C) $-\mathrm{NH}_{2} \mathrm{~N}$ atoms is observed, with the sum of the valence angles being $360(5)^{\circ}$ and $359(5)^{\circ}$. The packing shows similarities with neutral $\mathbf{1}$. Also in this case, molecules form planar ionic/H-bonded layers through $\mathrm{N}-\mathrm{H}$ donor and $\mathrm{N}$ acceptors present in the cation molecule and $\mathrm{O}$ and $\mathrm{N}$ acceptors of the dinitramide anion (Figure $4 b, c)$. The layers are parallel to the lattice plane $\overline{1} 21$ ( 121 is the most intense reflection of the diffraction pattern). The stacking distance of the planes is shorter than $1, d_{\overline{1} 21}=3.11 \AA$. The extended network of strong $\mathrm{H}$ bonds and the ionic interactions between cations and anions account for the significantly higher density of the crystal, which is $1.837 \mathrm{~g} / \mathrm{cm}^{3}$ at $-100{ }^{\circ} \mathrm{C}$.

The salts in which the triamine molecule is present as a dication, i.e., compounds 3-6 of Chart 3, were easily prepared by dissolving neutral $\mathbf{1}$ in a water solution of the corresponding strong inorganic acid (hydrobromic, perchloric, and nitric). In all of the salts studied, the tautomer present is $1 \mathrm{H}-1^{\prime} \mathrm{H}-4 \mathrm{H} \mathrm{s}$ trans (Chart 1). So, protonation (single or double) of neutral 1 is always at the ring $\mathrm{N}$ atoms. This is expected because the electron-donor character of the amino groups can stabilize the positive charge of the cation; as a result, the geometry around

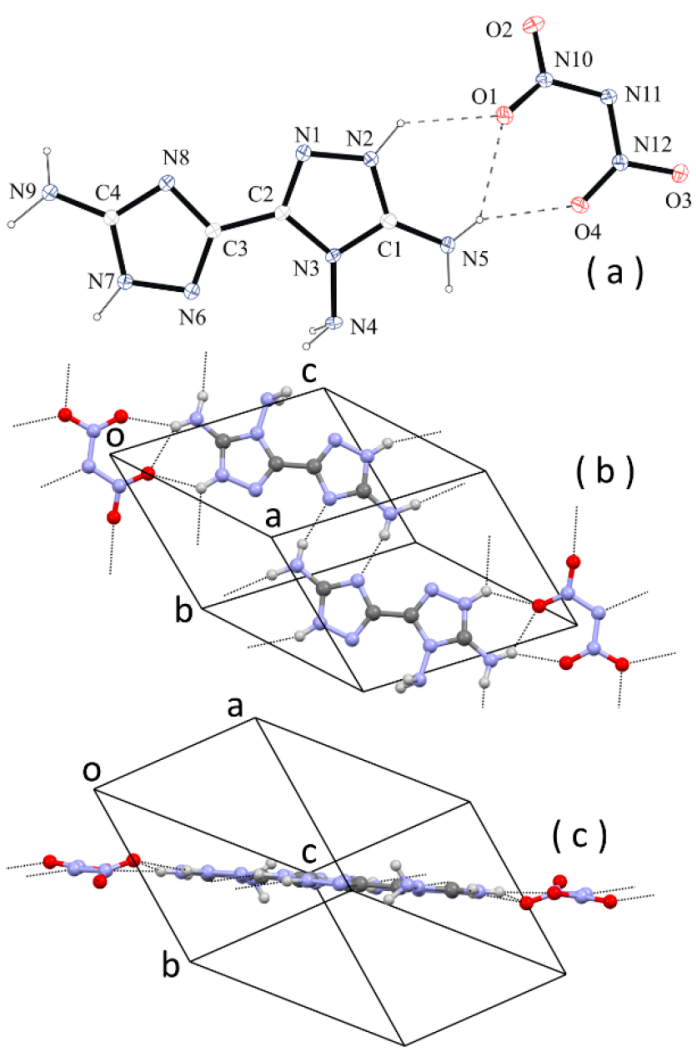

Figure 4. (a) ORTEP diagram of the crystallographic independent unit of $\left(\mathrm{C}_{4} \mathrm{H}_{8} \mathrm{~N}_{9}\right)\left(\mathrm{N}_{3} \mathrm{O}_{4}\right)$. (b) Face view of a layer of $\mathrm{H}$-bonded molecules. (c) Edge view of the same layer. Some $\mathrm{H}$ bonds are indicated by dashed lines.

the amino (C) $-\mathrm{NH}_{2} \mathrm{~N}$ atoms is trigonal-planar in all of the structures of the dications studied.

Some features of the crystal structure of the bromide salt are shown in Figure 5.

Again, the structure is of the stacked-layer type. The layers of ionic/H-bonded molecules (Figure $5 b, c$ ) are parallel to the lattice plane $1 \overline{2} 2$, with a short stacking distance of $d_{1 \overline{2} 2}=3.13$ $\AA$. The stacking between the layers is accomplished through strong $\mathrm{H}$ bonds between bromide ion acceptors and $\mathrm{N}-\mathrm{NH}_{2}$ donors, with the formation of $R_{4}^{2}(8)$ ring patterns (Figure $5 c$ ).

The energetic perchlorate salt is interesting because in the crystal the $\mathrm{N}$-rich dication is fully surrounded by oxidizing tetrahedral perchlorate anions. The conformation of the dication is again flat, with the dihedral angle between the average planes of the two rings being $5.8(2)^{\circ}$. The layers of ionic/H-bonded molecules (Figure $6 \mathrm{a}, \mathrm{b}$ ) are parallel to the lattice plane $11 \overline{2}$, with a stacking distance of $d_{11 \overline{2}}=3.22 \AA$.

The same feature is also present in the packing of the energetic nitrate salt, with the dication surrounded by trigonalplanar nitrate ions (Figure 7). In the nitrate salt, however, the dication shows the maximum deviation from planarity within the set of investigated compounds. In fact, the dihedral angle between the two pentatomic rings is $15.0(2)^{\circ}$. The layers of ionic/H-bonded molecules (Figure $7 \mathrm{a}, \mathrm{b}$ ) are parallel to the lattice plane 211 , with a stacking distance of $d_{211}=3.32 \AA$.

We have also crystallized the dication with the tetrachlorozincate complex anion (Figure 8). The crystal structure is stabilized by many $\mathrm{N}-\mathrm{H} \cdots \mathrm{Cl} \mathrm{H}$ bonds that are distributed over the full length of the $\mathrm{N}$-rich molecule ion (Figure 8a). The 

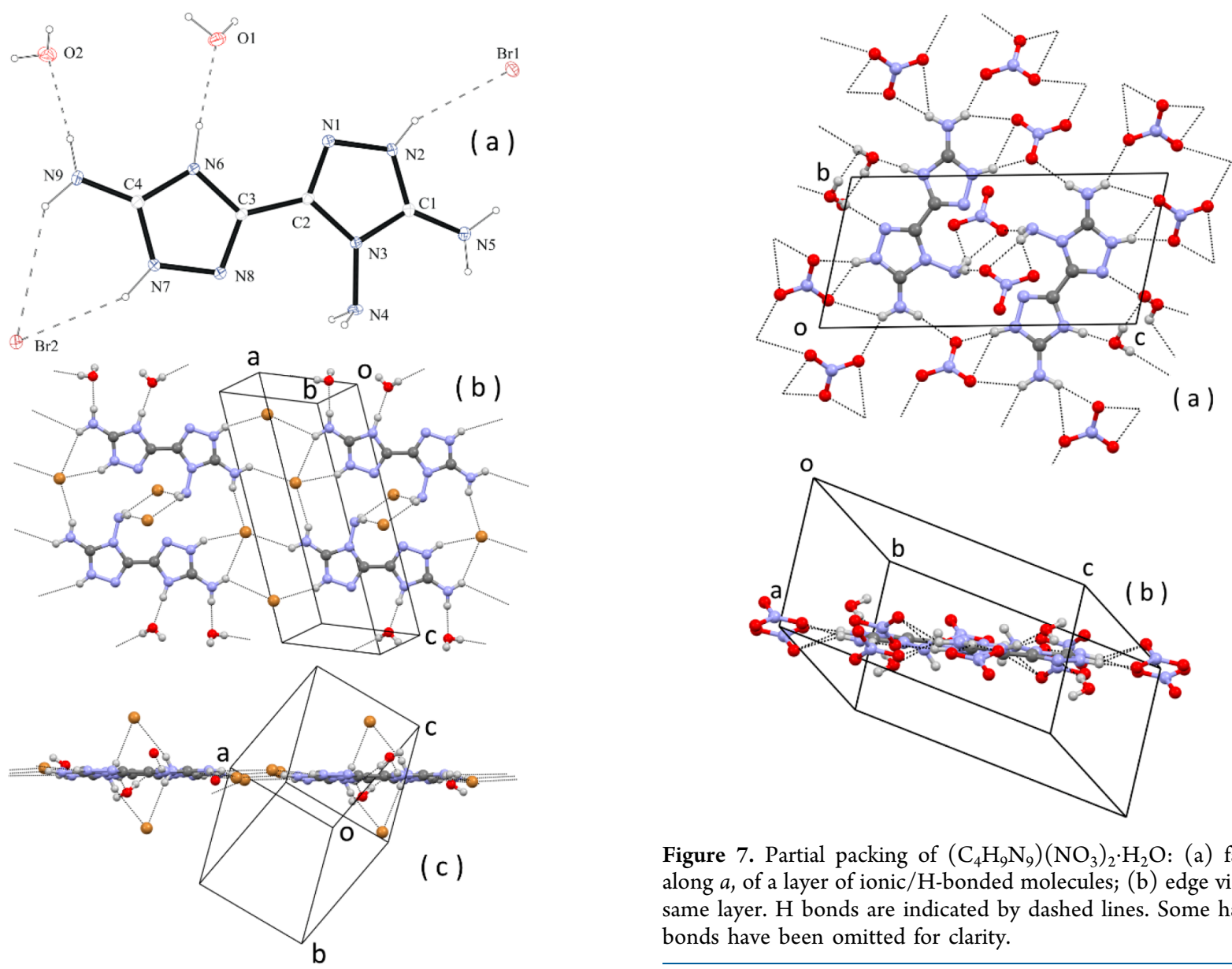

Figure 7. Partial packing of $\left(\mathrm{C}_{4} \mathrm{H}_{9} \mathrm{~N}_{9}\right)\left(\mathrm{NO}_{3}\right)_{2} \cdot \mathrm{H}_{2} \mathrm{O}$ : (a) face view, along $a$, of a layer of ionic/H-bonded molecules; (b) edge view of the same layer. $\mathrm{H}$ bonds are indicated by dashed lines. Some hanging $\mathrm{H}$ bonds have been omitted for clarity.

Figure 5. Crystal structure of $\left(\mathrm{C}_{4} \mathrm{H}_{9} \mathrm{~N}_{9}\right) \mathrm{Br}_{2} \cdot 2 \mathrm{H}_{2} \mathrm{O}$ : (a) ORTEP diagram of the crystallographic independent unit; (b) face view of a layer of ionic/H-bonded molecules; (c) edge view of the same layer. Some $\mathrm{H}$ bonds are indicated by dashed lines. Some hanging $\mathrm{H}$ bonds have been omitted for clarity.

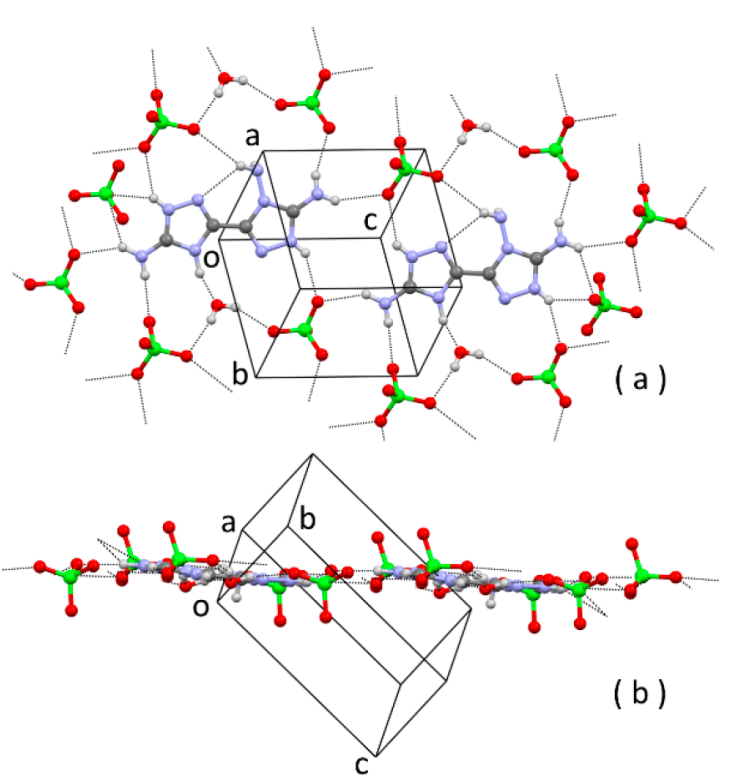

Figure 6. Partial packing of $\left(\mathrm{C}_{4} \mathrm{H}_{9} \mathrm{~N}_{9}\right)\left(\mathrm{ClO}_{4}\right)_{2} \cdot \mathrm{H}_{2} \mathrm{O}$ : (a) face view of a layer of ionic/H-bonded molecules; (b) edge view of the same layer. $\mathrm{H}$ bonds are indicated by dashed lines. Some hanging $\mathrm{H}$ bonds have been omitted for clarity.

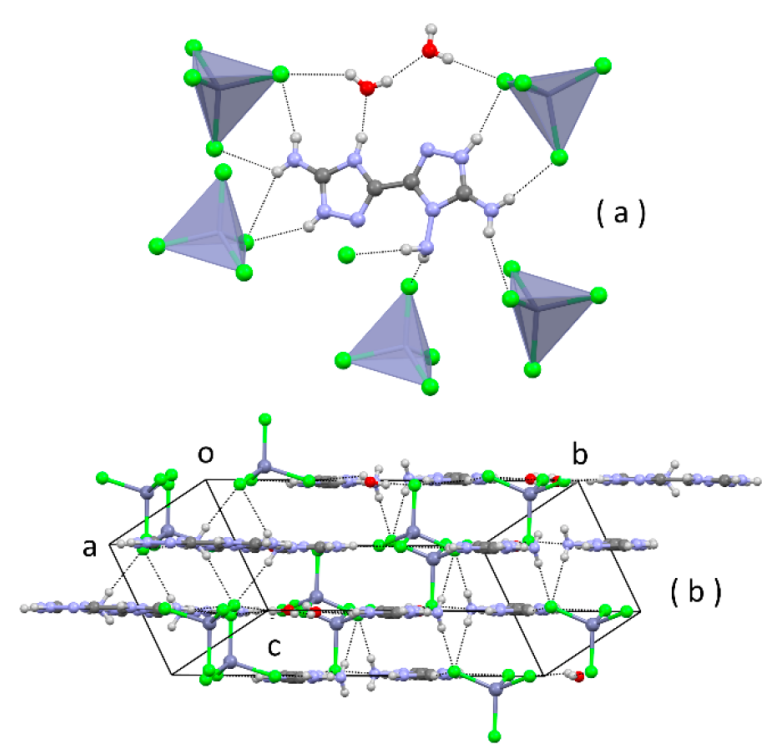

Figure 8. Crystal structure of $\left(\mathrm{C}_{4} \mathrm{H}_{9} \mathrm{~N}_{9}\right) \mathrm{ZnCl}_{4} \cdot 2 \mathrm{H}_{2} \mathrm{O}$ : (a) view of the cation, water molecules, and some $\mathrm{H}$-bonded tetrachlorozincate anions; (b) edge view of layers of ionic/H-bonded ions. Hanging contacts have been omitted for clarity.

layers of ionic/H-bonded molecules (Figure $8 \mathrm{~b}$ ) are parallel to the lattice plane 102 , with a stacking distance of $d_{102}=3.16 \AA$.

Thanks to the amphoteric properties of 1 (Chart 1 and Table 2), we have tried to crystallize salts of the triamine anion with inorganic cations $\left(\mathrm{Na}^{+}, \mathrm{K}^{+}\right.$, and $\left.\mathrm{NH}_{4}^{+}\right)$. As a matter of fact, neutral triamine is soluble in inorganic acids (e.g., $\mathrm{HCl}$, 
$\mathrm{HBr}$, and $\left.\mathrm{HClO}_{4}\right)$ and inorganic bases $\left(\mathrm{NaOH}_{\mathrm{aq}}, \mathrm{KOH}_{\mathrm{aq}}\right.$, and aqueous ammonia). However, crystallization of neutral $\mathbf{1}$ from aqueous ammonia yielded crystals of hydrated neutral $\mathbf{1}$. This result can be rationalized if we observe that the product of the acid constant of $\mathbf{1}\left(K_{\mathrm{a} 3}\right.$ in Table 2) and of $K_{\mathrm{b}}$ of ammonia $\left(1.774 \times 10^{-5} \text { at } 25^{\circ} \mathrm{C}\right)^{20}$ is almost equal to $K_{w}$, and so the equilibrium constant of the reaction between ammonia and $\mathbf{1}$ is almost unitary. On the other hand, we have successfully crystallized the sodium and potassium salts of the anion. The crystal structure of $\mathrm{K}\left(\mathrm{C}_{4} \mathrm{H}_{6} \mathrm{~N}_{9}\right) \cdot 2 \mathrm{H}_{2} \mathrm{O}$ is reported in Figure 9 .

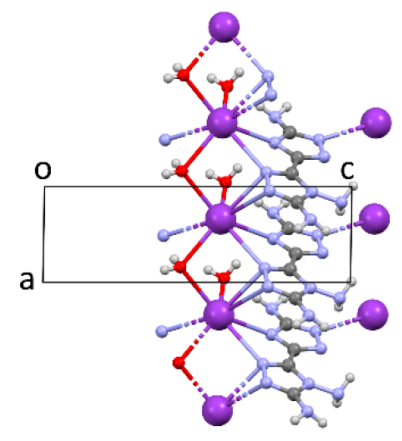

(a)

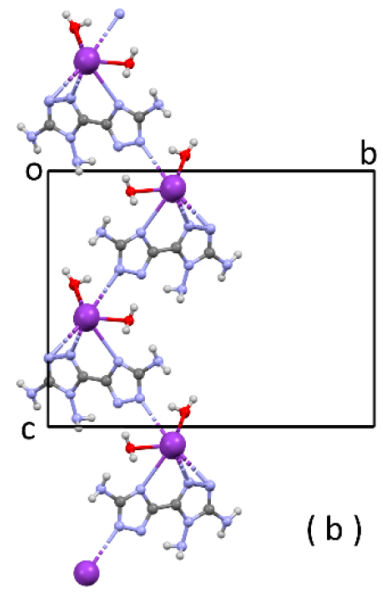

(b)
Figure 9. Partial packing of $\mathrm{K}\left(\mathrm{C}_{4} \mathrm{H}_{6} \mathrm{~N}_{9}\right) \cdot 2 \mathrm{H}_{2} \mathrm{O}$ : (a) projection along $b$; (b) projection along $a$.

In the molecular structure of the anion, the geometry around the (C) $-\mathrm{NH}_{2} \mathrm{~N}$ atom is again pyramidal the sum of the valence angles is $337(2)^{\circ}$ and $347(2)^{\circ}$, and this is expected because the electron excess of the anion reduces conjugation of the (C) $-\mathrm{NH}_{2}$ amino groups toward the rings. The tendency toward the formation of layers is no longer observed because the packing is mainly driven by the coordination geometry of the anionic ligand to the metal ion. As is evident from Figure 9, each anion acts as a tetradentate ligand by four ring $\mathrm{N}$ atoms. One $\mathrm{N}$ atom is $\mu_{2}$ between two $\mathrm{K}^{+}$ions, and a water molecule is also $\mu_{2}$-bridging between the same $\mathrm{K}^{+}$ions. In this way, infinite chains running along $a$ are formed by simple translation (Figure 9a). Chains are also formed running along $c$, and they are generated by the glide operation of the space group $P 2_{1} / c$ (Figure 9b). Altogether, a 2D coordination network is generated.

Characterization of Energetic Materials. In Figure 10 is reported the thermogravimetric analysis (TGA) of $\mathbf{1}$ and of energetic salts of the $\mathbf{1}$ cation or dication with oxidizing anions [differential scanning calorimetry (DSC) analysis is reported in the SI].

The neutral compound shows a very remarkable thermal stability in air. After an initial loss of hydration water at about $80{ }^{\circ} \mathrm{C}$, the anhydrous sample is stable up to $347{ }^{\circ} \mathrm{C}$. Among similar N-rich triazoles reported in the literature, ${ }^{6} \mathbf{1}$ has the best thermal stability in air. The thermal stability of the salts of the dication (perchlorate and nitrate) is lower. The dinitramide salt, in which triamine is present as a monocation, has a very clean TGA curve: it is fully stable up to $230{ }^{\circ} \mathrm{C}$, when it suddenly decomposes, losing $85 \%$ by weight, with an almost vertical TGA curve (green curve of Figure 10). Among the many N-rich dinitramide salts reported so far in the literature as energetic materials, ${ }^{6}$ the highest thermal stability is shown

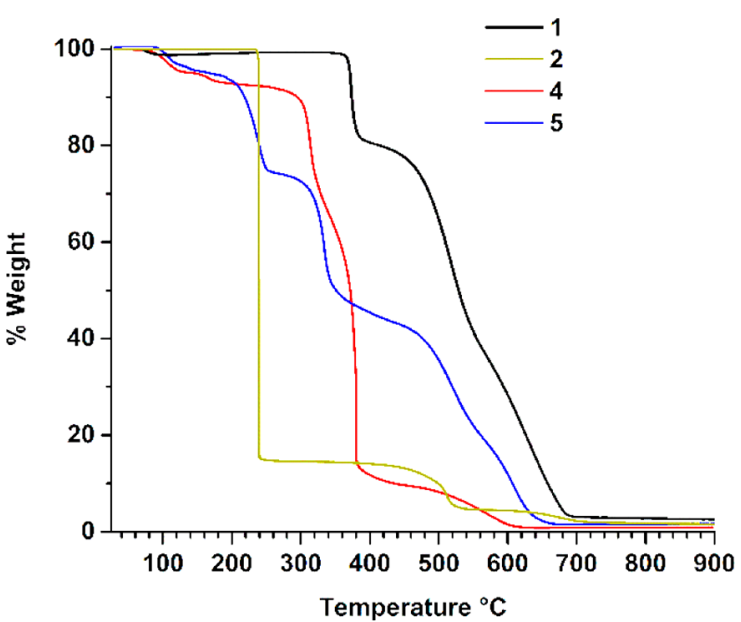

Figure 10. TGA of 1 and of some of its salts in air. Heating rate $10 \mathrm{~K} /$ min.

by FOX-12 ( $N$-guanylurea dinitramide), with $T_{\mathrm{d}}=215^{\circ} \mathrm{C} .^{21}$ The thermal stability of nitramide $\mathbf{2}$ is significantly higher.

The impact (IS), friction (FS), and electrostatic discharge (ESD) sensitivities of $\mathbf{1}$ and some of its energetic salts were measured experimentally (grain size 100-500 $\mu \mathrm{m}$ ) and are listed in Table 3. On the basis of the computed enthalpies of formation (see the $\mathrm{SI}$ ), the detonation parameters $\left(V_{\mathrm{oD}}=\right.$ velocity of detonation, $P_{\mathrm{C}-\mathrm{J}}=$ detonation pressure, and $Q_{\mathrm{ex}}=$ heat of detonation) were calculated with the EXPLOS program $^{23}$ and are also reported in Table 3.

Since the development of RDX (1,3,5-trinitro-1,3,5triazacyclohexane or cyclonite), any newly synthesized energetic compounds must face RDX, particularly in terms of the detonation pressure and detonation velocity, which are very important parameters in secondary explosives. For these reasons, the energetic properties of RDX have been added in Table 3 for a direct comparison. We have also added to Table 3 the literature data ${ }^{2}$ for two reference energetic salts containing inorganic anions: 5-aminotetrazolium dinitramide (HAT-DN) and 5-aminotetrazolium nitrate (5-ATN). Energetic compounds should also be stable with respect to the temperature, have a high density, be safe to handle, and be cheap to synthesize. In terms of the thermal stability, both 1 and 2 surpass the $200{ }^{\circ} \mathrm{C}$ benchmark and so largely outperform RDX, as well as HAT-DN and 5-ATN. 2 slightly outperforms RDX and 5-ATN also in the detonation velocity, while its performances in terms of the detonation pressure are slightly lower. Concerning the experimentally determined sensitivities, $\mathbf{1}$ is insensitive to both impact and friction. $\mathbf{2}$ is impactsensitive, with a measured value in the range observed for other $\mathrm{N}$-rich dinitramides: ammonium dinitramide (ADN) $5 \mathrm{~J}$, triaminoguanidinium dinitramide (TAGDN) $2 \mathrm{~J},{ }^{6}$ and HATDN. On the other hand, 2 is friction-insensitive, a significant result, inasmuch as other $\mathrm{N}$-rich dinitramides, including HAT$\mathrm{DN}$, have high sensitivity toward friction (ADN $72 \mathrm{~N}$ and TAGDN $24 \mathrm{~N}) .^{6} 4$ is impact-sensitive and moderately sensitive to friction, while $\mathbf{5}$ is less impact-sensitive than $\mathbf{2}$ and $\mathbf{4}$ and friction-insensitive, and so it is better performing than nitrate 5-ATN. The lower impact sensitivity of 5, compared with 2 and 4 , can be related to some of the structural features discussed above. In $\mathbf{5}$, the dication shows the highest deviation from coplanarity of the two rings, and this produces an increase of the stacking distance between the planes of ionic/ 
Table 3. Energetic Properties and Detonation Parameters of Compounds 1, 2, 4, and 5 and the Reference Compounds RDX, HAT-DN, and 5-ATN

\begin{tabular}{|c|c|c|c|c|c|c|c|c|c|}
\hline compound & $\rho^{a}\left(\mathrm{~g} / \mathrm{cm}^{3}\right)$ & $\rho^{b}\left(\mathrm{~g} / \mathrm{cm}^{3}\right)$ & $T_{\mathrm{d}}\left({ }^{\circ} \mathrm{C}\right)^{c}$ & IS $(\mathrm{J})^{d}$ & $\mathrm{FS}(\mathrm{N})^{e}$ & $\operatorname{ESD}(\mathrm{J})^{f}$ & $V_{\mathrm{oD}}(\mathrm{m} / \mathrm{s})^{g}$ & $P_{\mathrm{C}-\mathrm{J}}(\mathrm{kbar})^{h}$ & $Q_{\mathrm{ex}}(\mathrm{kJ} / \mathrm{kg})^{i}$ \\
\hline 1 & 1.629 & 1.599 & 347 & $>40$ & $>360$ & 1 & 7681 & 194 & -2378 \\
\hline 2 & 1.837 & 1.803 & 230 & 4 & $>360$ & 0.1 & 8948 & 311 & -4496 \\
\hline 4 & 1.908 & 1.873 & 270 & 4 & 192 & 0.1 & 7033 & 191 & -1711 \\
\hline 5 & 1.773 & 1.740 & 210 & $>25$ & $>360$ & 0.6 & 8092 & 246 & -3289 \\
\hline $\mathrm{RDX}^{j}$ & 1.806 & & 204 & 7.5 & 120 & 0.20 & 8861 & 345 & -5845 \\
\hline HAT-DN $^{k}$ & 1.856 & & 117 & 2 & 20 & 0.75 & 9429 & 384 & 6186 \\
\hline $5-\mathrm{ATN}^{k}$ & & 1.807 & 190 & 10 & $>324$ & & 8898 & 357 & -4603 \\
\hline
\end{tabular}

${ }^{a}$ Cystallographic density at $-100{ }^{\circ} \mathrm{C}$. ${ }^{b}$ Calculated density at $298 \mathrm{~K}$, according to ref $22 .{ }^{c}$ Decomposition temperature (onset) for the anhydrous sample in the TGA runs of Figure 10. ${ }^{d}$ Impact sensitivity (BAM drop hammer). ${ }^{e}$ Friction sensitivity (BAM friction tester). ${ }^{f}$ Electrostatic discharge sensitivity. ${ }^{g}$ Calculated detonation velocity. ${ }^{h}$ Calculated detonation pressure. ${ }^{i}$ Calculated heat of detonation. ${ }^{j}$ Data taken from ref $6 .{ }^{k}$ Data taken from ref 2 .

H-bonded molecules and a reduced density. Nitramide 2 can be considered to be the most interesting energetic material within the set investigated, although its impact sensitiveness hinders its use as main explosive. Altogether, the salt compounds described here could be of potential interest as propellant charges, as additives in propellant charges, or as gas generators.

\section{CONCLUSION}

We have presented the $\mathrm{N}$-rich bis(triazole) compound $\mathbf{1}$ and have investigated its acid-base behavior. An interesting feature of $\mathbf{1}$ is the existence of well-defined $\mathrm{pH}$ intervals in which it is present in solution as neutral, singly protonated, doubly protonated, and deprotonated forms. This discloses the possibility of selective crystallization from a solution of salts containing different ionic forms of $\mathbf{1}$, which we have experimentally realized. In fact, salts containing all of the ionic species of $\mathbf{1}$ were crystallized and structurally characterized by X-ray analysis. For some salts containing energetic counterions (nitrate, perchlorate, and dinitramide), the sensitivities were experimentally determined, and the detonation parameters were computed.

Our present study paves the way to more specific studies of energetic materials based on $\mathbf{1}$. Because of the existence of two different protonated forms, the set of possible energetic salts of 1 to be investigated is very large in principle. As an example, further studies could be directed to a comparison of the properties of energetic salts containing the same counterion but different protonated forms of 1 .

\section{EXPERIMENTAL PART}

Caution! The compounds in this work are potentially energetic materials that could explode under certain conditions (such as impact, friction, or electric discharge). Experiments should be performed on a small scale. Appropriate safety precautions, including the use of safety shields and personal protection (safety glasses, ear plugs, and gloves), are suggested at all times during handling of these compounds.

General Procedures. All reagents were of analytical grade and were used without further purification. Melting points were determined by temperature-controlled optical microscopy (Zeiss Axioskop polarizing microscope equipped with a Linkam PR600 heating stage). TGA was performed with a PerkinElmer TGA 4000 apparatus. DSC analysis was performed with a PerkinElmer Pyris instrument. NMR spectra were recorded with a Bruker spectrometer operating at $400 \mathrm{MHz}$, in deuterated dimethyl sulfoxide (DMSO- $d_{6}$ ). Electrospray ionization (ESI) mass spectrometry (MS) analyses were recorded with an Applied Biosystems API 2000 mass spectrometer equipped with an electrospray source used in the positive mode.
Elemental analyses were performed using a FlashEA 1112 analyzer (Thermo Fisher Scientific Inc.) and a Netsch STA 429 apparatus.

Synthesis of 1. Commercial 5-amino-1H-1,2,4-triazole-3-carboxylic acid $\left(5.00 \mathrm{~g}, 4.90 \times 10^{-2} \mathrm{~mol}\right)$ and diaminoguanidine monohydrochloride $\left(6.40 \mathrm{~g}, 5.09 \times 10^{-2} \mathrm{~mol}, 30 \%\right.$ excess by mol $)$ were finely ground in a mortar. The mixture was added in portions, under mechanical stirring, to a beaker containing poly(phosphoric acid) (40 g) at $100{ }^{\circ} \mathrm{C}$ (Scheme S1). After a few minutes, the evolution of gaseous $\mathrm{HCl}$ was observed from the reaction mixture. The temperature of the pasty reaction mixture was increased to $150{ }^{\circ} \mathrm{C}$, and the mixture reacted for $5 \mathrm{~h}$ under stirring. Afterward, the mixture was poured into cold water $(100 \mathrm{~mL})$, and the $\mathrm{pH}$ of the resulting solution was increased to 5 by the addition of a concentrated solution of $\mathrm{NaOH}$. Raw 1, in the form of an off-white solid, was obtained, filtered, washed with cold water, and dried in an oven at $100{ }^{\circ} \mathrm{C}$. Raw $1(5.5 \mathrm{~g})$ was suspended in water $(100 \mathrm{~mL})$. Concentrated $\mathrm{HCl}(37 \%$; $20 \mathrm{~mL}$ ) was added drop by drop under stirring, and the suspension was heated. Upon addition of the acid and heating, the suspension progressively became a clear, pale-brown solution. The solution was kept boiling under stirring until the volume reduced $50 \mathrm{~mL}$. Then it was cooled to room temperature, and a white solid (the dichlorhydrate salt) formed. The solid was recovered by filtration and washed on the filter with ethanol. Then it was dried in an oven at $110{ }^{\circ} \mathrm{C}$. A total of $4.9 \mathrm{~g}$ of the dichlorhydrate salt was obtained. The salt product was solved in hot water (about $100 \mathrm{~mL}$ ). A $1 \mathrm{M}$ solution of $\mathrm{KOH}$ was added drop by drop until the $\mathrm{pH}$ was $6-7$. A crystalline precipitate formed. The suspension was cooled to room temperature, and the precipitate was filtered, washed with water on the filter, and dried in an oven at $110^{\circ} \mathrm{C}$ overnight. In this way, $3.98 \mathrm{~g}$ of pure 1 was obtained. Yield: $3.98 \mathrm{~g}(45 \%)$. Mp: $347{ }^{\circ} \mathrm{C}(\mathrm{dec}) .{ }^{1} \mathrm{H}$ NMR $(400$ $\left.\mathrm{MHz}, \mathrm{DMSO}-d_{6}\right): \delta 5.67(\mathrm{~s}, 2 \mathrm{H}), 5.77(\mathrm{~s}, 2 \mathrm{H}), 6.18(\mathrm{~s}, 2 \mathrm{H}) 12.33(\mathrm{~s}$, $1 \mathrm{H}) .{ }^{13} \mathrm{C}$ NMR (100 MHz, DMSO- $\left.d_{6}\right): \delta 142.59,150.58155 .47$ 157.24. MS (ESI, positive mode). Calcd for $\mathrm{C}_{4} \mathrm{H}_{7} \mathrm{~N}_{9}: m / z 181.16$. Found: $m / z 182.0\left(\mathrm{M}^{+} \cdot \mathrm{H}\right)$. Anal. Calcd for $\mathrm{C}_{4} \mathrm{H}_{7} \mathrm{~N}_{9} \cdot 0.5 \mathrm{H}_{2} \mathrm{O}: \mathrm{C}$, 25.26; H, 4.24; N, 66.29. Found: C, 25.86; H, 3.69; N, 67.00.

Synthesis of $\left(\mathrm{C}_{4} \mathrm{H}_{8} \mathrm{~N}_{9}\right)\left(\mathrm{N}_{3} \mathrm{O}_{4}\right) .\left(\mathrm{C}_{4} \mathrm{H}_{9} \mathrm{~N}_{9}\right)\left(\mathrm{ClO}_{4}\right)_{2}(0.667 \mathrm{~g}, 1.75$ $\mathrm{mmol}$ ) was dissolved in $25 \mathrm{~mL}$ of hot water. The solution was added to another solution containing $\mathrm{KN}_{3} \mathrm{O}_{4}(0.508 \mathrm{~g}, 3.50 \mathrm{mmol})$ and 2 $\mathrm{mL}$ of water. Pale-pink prismatic crystals of the triamine monocation salt were obtained by slow cooling to room temperature from a warm water bath $\left(70{ }^{\circ} \mathrm{C}\right)$ with quantitative yield. Anal. Calcd for $\left(\mathrm{C}_{4} \mathrm{H}_{8} \mathrm{~N}_{9}\right)\left(\mathrm{N}_{3} \mathrm{O}_{4}\right)$ : C, 16.66; H, 2.80; N, 58.32. Found: C, 16.31; $\mathrm{H}, 2.43 ; \mathrm{N}, 58.81$.

Synthesis of $\left(\mathrm{C}_{4} \mathrm{H}_{9} \mathrm{~N}_{9}\right) \mathrm{Br}_{2}$. A total of 10 drops of a $\mathrm{HBr}$ concentrated solution $(48 \%, \mathrm{v} / \mathrm{v})$ was added to a hot water solution of $30 \mathrm{mg}$ of $1(0.150 \mathrm{mmol})$. Prismatic colorless crystals of the dihydrate bromide salt were obtained by slow solvent evaporation at room temperature in 2 days, with $86 \%$ yield. Anal. Calcd for $\left(\mathrm{C}_{4} \mathrm{H}_{9} \mathrm{~N}_{9}\right) \mathrm{Br}_{2} \cdot 2 \mathrm{H}_{2} \mathrm{O}: \mathrm{C}, 12.67 ; \mathrm{H}, 3.46 ; \mathrm{N}, 33.26$. Found: $\mathrm{C}, 12.42 ; \mathrm{H}$, $3.31 ; \mathrm{N}, 33.69$.

Synthesis of $\left(\mathrm{C}_{4} \mathrm{H}_{9} \mathrm{~N}_{9}\right)\left(\mathrm{ClO}_{4}\right)_{2}$. A total of 5 drops of a $\mathrm{HClO}_{4}$ concentrated solution $(70 \%, \mathrm{v} / \mathrm{v})$ was added to a hot water solution of 
$30 \mathrm{mg}$ of 1 (0.150 mmol). Prismatic colorless crystals of the perchlorate salt hydrate were obtained by slow evaporation at room temperature in 2 days, with $90 \%$ yield. The sample was dehydrated by keeping it in a desiccator over $\mathrm{CaCl}_{2}$ for 1 week. Anal. Calcd for $\mathrm{C}_{4} \mathrm{H}_{9} \mathrm{~N}_{9}\left(\mathrm{ClO}_{4}\right)_{2}$ : C, 12.57; H, 2.37; N, 32.99. Found: C, 12.51; H, 2.64; N, 32.38 .

Synthesis of $\left(\mathrm{C}_{4} \mathrm{H}_{9} \mathrm{~N}_{9}\right)\left(\mathrm{NO}_{3}\right)_{2}$. A total of 5 drops of a $\mathrm{HNO}_{3}$ concentrated solution $(65 \%, \mathrm{v} / \mathrm{v})$ was added to a hot water solution of $30 \mathrm{mg}$ of $1(0.150 \mathrm{mmol})$. Pale-pink lozenge crystals of the nitrate salt dihydrate was obtained by slow cooling to room temperature from a warm water bath $\left(70{ }^{\circ} \mathrm{C}\right)$ with quantitative yield. Anal. Calcd for $\left(\mathrm{C}_{4} \mathrm{H}_{9} \mathrm{~N}_{9}\right)\left(\mathrm{NO}_{3}\right)_{2} \cdot \mathrm{H}_{2} \mathrm{O}: \mathrm{C}, 14.77 ; \mathrm{H}, 3.41 ; \mathrm{N}, 47.37$. Found: $\mathrm{C}$, 14.99; H, 3.75; N, 46.98 .

Synthesis of $\left(\mathrm{C}_{4} \mathrm{H}_{9} \mathrm{~N}_{9}\right)\left(\mathrm{ZnCl}_{4}\right) . \quad 1 \quad(30 \mathrm{mg}, 0.150 \mathrm{mmol})$ was dissolved in $1 \mathrm{~mL}$ of hot water. The solution was added to another solution containing $\mathrm{ZnCl}_{2}(20 \mathrm{mg}, 0.150 \mathrm{mmol})$, water $(1 \mathrm{~mL})$, and 10 drops of a concentrated $\mathrm{HCl}$ solution $(37 \%, \mathrm{v} / \mathrm{v})$. The solution was left undisturbed, and pale-brown prismatic crystals were obtained in 2 days, with $60 \%$ yield. Anal. Calcd for $\left(\mathrm{C}_{4} \mathrm{H}_{9} \mathrm{~N}_{9}\right) \mathrm{ZnCl}_{4} \cdot 2 \mathrm{H}_{2} \mathrm{O}$ : $\mathrm{C}$, 11.24; H, 3.06; N, 29.49. Found: C, 11.71; H, 2.83; N, 28.97.

Synthesis of $K\left(\mathrm{C}_{4} \mathrm{H}_{6} \mathrm{~N}_{9}\right)$. Brown prismatic crystals of the K$\left(\mathrm{C}_{4} \mathrm{H}_{6} \mathrm{~N}_{9}\right)$ dihydrate salt were grown in 1 day by slow cooling to room temperature of a hot water solution containing $200 \mathrm{mg}$ of 1 (1 $\mathrm{mmol}$ ) and a $\mathrm{KOH}$ concentrated solution $(2 \mathrm{~mL})$ with quantitative yield. Anal. Calcd for $\mathrm{K}\left(\mathrm{C}_{4} \mathrm{H}_{6} \mathrm{~N}_{9}\right) \cdot 2 \mathrm{H}_{2} \mathrm{O}: \mathrm{C}, 18.82 ; \mathrm{H}, 3.95 ; \mathrm{N}, 49.38$. Found: C, 18.23; H, 4.42; N, 49.27.

Computational Details. Quantum-chemical computations were carried with the Gaussian 16 package by using density functional theory (DFT). ${ }^{24}$ The B3LYP functional was employed throughout in conjunction with the $6-31+\mathrm{G}^{* *}$ basis set. B3LYP has proven to give excellent performance, nearly reproducing experimental electrical and optical properties for organic molecules. ${ }^{25,26}$ Solvent (water) effects were included by the polarizable continuum model. ${ }^{27}$ The nature of the located stationary points was verified by checking the eigenvalues of the Hessian matrix; all of the minimum-energy structures have positive eigenvalues. For all tautomers of Chart 2, a molecularmechanics scan based on the Spartan program was performed, in order to find possible conformers.

Acid-Base Equilibria. The protolytic equilibria of $\mathbf{1}$ were studied by $\mathrm{UV}$-vis absorption spectroscopy in $0.5 \mathrm{M} \mathrm{NaCl}$, as the ionic medium, following a procedure already described ${ }^{8,18}$ and detailed in the SI. The experiments were performed as acid-base titrations at a constant total concentration of $1\left(c=5.01 \times 10^{-5} \mathrm{M}\right)$. The investigated $\mathrm{pH}$ range extends from 0.3 to 12 . For each experimental point, the equilibrium free proton concentration was evaluated from the measured electromotive force at the ends of the galvanic cell GE/ TS/RE, where TS indicates the test solution, GE is the glass electrode, and $\mathrm{RE}$ is a reference electrode $\left[0.5 \mathrm{M} \mathrm{NaCl} \mathrm{Hg}_{2} \mathrm{Cl}_{2} \mathrm{IHg}(\mathrm{Pt})\right]$ placed outside but electrically connected to TS through a salt bridge. All of the experiments were carried out in air, in a thermostat at $25.00 \pm$ $0.03{ }^{\circ} \mathrm{C}$. Absorption spectra were recorded with a Varian Cary 50 UV-vis spectrophotometer using a $1 \mathrm{~cm}$ cell. The primary spectrophotometric data $(A, \mathrm{pH}$, and $\lambda)$ were elaborated graphically ${ }^{28}$ and numerically by using the HYPSPEC 2008 program $^{29}$ for determination of the equilibrium constants in solution.

X-ray Analysis. All data for crystal structure determinations were measured on a Bruker-Nonius Kappa CCD diffractometer equipped with an Oxford Cryostream 700 apparatus, using graphitemonochromated Mo $\mathrm{K} \alpha$ radiation $(\lambda=0.71073 \AA)$. Reduction of data and semiempirical absorption correction were done using the SADABS program. ${ }^{30}$ The structures were solved by direct methods (SIR97 program ${ }^{31}$ ) and refined by the full-matrix least-squares method on $F^{2}$ using the SHELXL-2015 program ${ }^{32}$ with the aid of the program $W_{i n G X}{ }^{33} \mathrm{H}$ atoms bonded to $\mathrm{N}$ atoms, which are essential in the identification of tautomers, and those bonded to $\mathrm{O}$ atoms in water molecules, were clearly found in difference Fourier maps as the first maxima, and in some cases, their coordinates were refined. For all $\mathrm{H}$ atoms, $U_{\text {iso }}=1.2 U_{\mathrm{eq}}$ of the carrier atom was assumed. Full crystal and refinement data are summarized in Tables S1 and S2. Analysis of the crystal packing was performed using the program Mercury. ${ }^{34}$ CCDC 2092331, 2092333, 2092335, 2092337, 2092339, 2092341, and 2092342 contain the supplementary crystallographic data for this paper (see the SI).

Sensitivity Testing. The impact sensitivity tests were carried out according to STANAG $4489^{35}$ modified instruction ${ }^{36}$ using a BAM (Bundesanstalt für Materialforschung) drophammer. ${ }^{37}$ The friction sensitivity tests were carried out according to STANAG $4487^{38}$ modified instruction $^{39}$ using the BAM friction tester. The classification of the tested compounds results from the "UN Recommendations on the Transport of Dangerous Goods". ${ }^{40}$ Additionally, all compounds were tested on the sensitivity toward electrical discharge using the Electric Spark Tester ESD 2010 EN. ${ }^{41}$

\section{ASSOCIATED CONTENT}

\section{Supporting Information}

The Supporting Information is available free of charge at https://pubs.acs.org/doi/10.1021/acs.inorgchem.1c02002.

Scheme of the synthesis of $1,{ }^{1} \mathrm{H}$ and ${ }^{13} \mathrm{C}$ NMR and mass spectra of $\mathbf{1}$, DSC thermograms of $\mathbf{1}$ and its energetic salts, detailed description of the UV-vis and electrochemical methods used in the study of the acidbase properties, full crystallographic details, full details of the computation of the energetic properties, and geometry of DFT-optimized tautomers/conformers (PDF)

\section{Accession Codes}

CCDC 2092331, 2092333, 2092335, 2092337, 2092339, 2092341, and2092342 contain the supplementary crystallographic data for this paper. These data can be obtained free of charge via www.ccdc.cam.ac.uk/data_request/cif, or by emailing data_request@ccdc.cam.ac.uk, or by contacting The Cambridge Crystallographic Data Centre, 12 Union Road, Cambridge CB2 1EZ, UK; fax: +44 1223336033.

\section{AUTHOR INFORMATION}

\section{Corresponding Author}

Roberto Centore - Department of Chemical Sciences, University of Naples Federico II, I-80126 Naples, Italy; (1) orcid.org/0000-0002-2797-0117;

Email: roberto.centore@unina.it

\section{Authors}

Emmanuele Parisi - Department of Chemical Sciences, University of Naples Federico II, I-80126 Naples, Italy; (1) orcid.org/0000-0002-9413-1372

Alessandro Landi - Department of Chemistry and Biology, University of Salerno, I-84084 Fisciano, Salerno, Italy; (1) orcid.org/0000-0003-3627-5535

Sandra Fusco - Department of Chemical Sciences, University of Naples Federico II, I-80126 Naples, Italy

Carla Manfredi - Department of Chemical Sciences, University of Naples Federico II, I-80126 Naples, Italy

Andrea Peluso - Department of Chemistry and Biology, University of Salerno, I-84084 Fisciano, Salerno, Italy; (1) orcid.org/0000-0002-6140-9825

Sabrina Wahler - Department of Chemistry, Energetic Materials Research, Ludwig-Maximilian University, D-81377 Münich, Germany

Thomas M. Klapötke - Department of Chemistry, Energetic Materials Research, Ludwig-Maximilian University, D-81377 Münich, Germany; 이이이.org/0000-0003-3276-1157

Complete contact information is available at: https://pubs.acs.org/10.1021/acs.inorgchem.1c02002 


\section{Author Contributions}

The manuscript was written through contributions of all authors, and all authors have given approval to the final version of the manuscript.

\section{Notes}

The authors declare no competing financial interest.

\section{ACKNOWLEDGMENTS}

Thanks are due to the COST Association for support and critical discussion within COST Action CA17120-Chemobrionics and to the CRdC NTAP of Regione Campania (Italy) for the X-ray facility.

\section{REFERENCES}

(1) Klapötke, T. M. Chemistry of High-Energy Materials, 5th ed.; de Gruyter: Berlin/Boston, 2019.

(2) Klapötke, T. M. Energetic Materials Encyclopedia, 2nd ed.; de Gruyter: Berlin/Boston, 2021; Vols. 1-3.

(3) Centore, R.; Carella, A.; Fusco, S. Supramolecular synthons in fluorinated and nitrogen-rich ortho-diaminotriazoles. Struct. Chem. 2011, 22, 1095-1103.

(4) Centore, R.; Fusco, S.; Capobianco, A.; Piccialli, V.; Zaccaria, S.; Peluso, A. Tautomerism in the Fused N-Rich Triazolotriazole Heterocyclic System. Eur. J. Org. Chem. 2013, 2013, 3721-3728.

(5) Centore, R.; Causà, M.; Fusco, S.; Carella, A. Short $\pi$-Stacking in N-Rich Ionic Aromatic compounds. Cryst. Growth Des. 2013, 13, $3255-3260$

(6) Klapötke, T. M.; Schmid, P. C.; Schnell, S.; Stierstorfer, J. Thermal stabilization of energetic materials by the aromatic nitrogenrich 4,4',5,5'-tetraamino-3,3'-bi-1,2,4-triazolium cation. J. Mater. Chem. A 2015, 3, 2658-2668.

(7) Klapötke, T. M.; Schmid, P. C.; Schnell, S.; Stierstorfer, J. 3,6,7Triamino-[1,2,4]triazolo[4,3-b][1,2,4]triazole: A Non-toxic, HighPerformance Energetic Building Block with Excellent Stability. Chem. - Eur. J. 2015, 21, 9219-9228.

(8) Parisi, E.; Capasso, D.; Capobianco, A.; Peluso, A.; Di Gaetano, S.; Fusco, S.; Manfredi, C.; Mozzillo, R.; Pinto, G.; Centore, R. Tautomeric and conformational switching in a new versatile $\mathrm{N}$-rich heterocyclic ligand. Dalton Trans. 2020, 49, 14452-14462.

(9) Gettings, M. L.; Davis Finch, S. E.; Sethia, A.; Byrd, E. F. C.; Zeller, M.; Piercey, D. G. Heterocyclic Nitrilimines and Their Use in the Synthesis of Complex High-Nitrogen Materials. Inorg. Chem. 2021, 60, 7607-7611.

(10) Tang, Y.; Yin, Z.; Chinnam, A. K.; Staples, R. J.; Shreeve, J. M. A Duo and a Trio of Triazoles as Very Thermostable and Insensitive Energetic Materials. Inorg. Chem. 2020, 59, 17766-17774.

(11) Xue, Y-b.; Xiong, H.-I.; Tang, J.; Cheng, G.-b.; Yang, H.-w. Exploring Application of 1,2,4-Triazole Energetic Salts: Gas Generating Agent, Propellant and Explosive Compositions. Propellants, Explos., Pyrotech. 2021, 46, 1070-1078.

(12) Wang, R.; Xu, H.; Guo, Y.; Sa, R.; Shreeve, J. M. Bis[3-(5nitroimino-1,2,4-triazolate)]-Based Energetic Salts: Synthesis and Promising Properties of a New Family of High-Density Insensitive Materials. J. Am. Chem. Soc. 2010, 132, 11904-11905.

(13) Cruz-Cabeza, A. J.; Groom, C. R. Identification, classification and relative stability of tautomers in the cambridge structural database. CrystEngComm 2011, 13, 93-98.

(14) Martin, Y. C. Let's not forget tautomers. J. Comput.-Aided Mol. Des. 2009, 23, 693-704.

(15) Tang, Y.; Huang, W.; Chinnam, A. K.; Singh, J.; Staples, R. J.; Shreeve, J. M. Energetic Tricyclic Polynitropyrazole and Its salts: Proton-Locking Effect of Guanidinium Cations. Inorg. Chem. 2021, $60,8339-8345$

(16) Todorov, A. R.; Nieger, M.; Helaja, J. Tautomeric Switching and Metal-Cation Sensing of Ligand-Equipped 4-Hydroxy-/4-oxo-1,4dihydroquinolines. Chem. - Eur. J. 2012, 18, 7269-7277.
(17) Deneva, V.; Dobrikov, G.; Crochet, A.; Nedeltcheva, D.; Fromm, K. M.; Antonov, L. Tautomerism as primary signaling mechanism in metal sensing: the case of amide group. Beilstein J. Org. Chem. 2019, 15, 1898-1906.

(18) Centore, R.; Manfredi, C.; Capobianco, A.; Volino, S.; Ferrara, M. V.; Carella, A.; Fusco, S.; Peluso, A. Solid State Separation and Isolation of Tautomers of Fused-Ring Triazolotriazoles. J. Org. Chem. 2017, 82, 5155-5161.

(19) Fusco, S.; Parisi, E.; Carella, A.; Capobianco, A.; Peluso, A.; Manfredi, C.; Borbone; Centore, R. Solid State Selection between Nearly Isoenergetic Tautomeric Forms Driven by Right HydrogenBonding Pairing. Cryst. Growth Des. 2018, 18, 6293-6301.

(20) Weast, R. C., Ed. CRC Handbook of Chemistry and Physics, 65th ed.; CRC Press Inc.: Boca Raton, FL, 1984.

(21) Östmark, H.; Bemm, U.; Bergman, H.; Langlet, A. Nguanylurea-dinitramide: a new energetic material with low sensitivity for propellants and explosives applications. Thermochim. Acta 2002, $384,253-259$.

(22) Xue, C.; Sun, J.; Kang, B.; Liu, Y.; Liu, X.; Song, G.; Xue, Q. The $\beta-\delta$-Phase Transition and Thermal Expansion of Octahydro1,3,5,7-Tetranitro-1,3,5,7-Tetrazocine. Propellants, Explos., Pyrotech. 2010, 35, 333-338.

(23) Sućeska, M. EXPLO5, version 6.05.02; Brodarski Institute: Zagreb, Croatia, 2018.

(24) Frisch, M. J.; Trucks, G. W.; Schlegel, H. B.; Scuseria, G. E.; Robb, M. A.; Cheeseman, J. R.; Scalmani, G.; Barone, V.; Petersson, G. A.; Nakatsuji, H.; Li, X.; Caricato, M.; Marenich, A. V.; Bloino, J.; Janesko, B. G.; Gomperts, R.; Mennucci, B.; Hratchian, H. P.; Ortiz, J. V.; Izmaylov, A. F.; Sonnenberg, J. L.; Williams-Young, D.; Ding, F.; Lipparini, F.; Egidi, F.; Goings, J.; Peng, B.; Petrone, A.; Henderson, T.; Ranasinghe, D.; Zakrzewski, V. G.; Gao, J.; Rega, N.; Zheng, G.; Liang, W.; Hada, M.; Ehara, M.; Toyota, K.; Fukuda, R.; Hasegawa, J.; Ishida, M.; Nakajima, T.; Honda, Y.; Kitao, O.; Nakai, H.; Vreven, T.; Throssell, K.; Montgomery, J. A., Jr.; Peralta, J. E.; Ogliaro, F.; Bearpark, M. J.; Heyd, J. J.; Brothers, E. N.; Kudin, K. N.; Staroverov, V. N.; Keith, T. A.; Kobayashi, R.; Normand, J.; Raghavachari, K.; Rendell, A. P.; Burant, J. C.; Iyengar, S. S.; Tomasi, J.; Cossi, M.; Millam, J. M.; Klene, M.; Adamo, C.; Cammi, R.; Ochterski, J. W.; Martin, R. L.; Morokuma, K. L.; Farkas, O.; Foresman, J. B.; Fox, D. J. Gaussian 16, revision C.01; Gaussian Inc.: Wallingford, CT, 2016.

(25) Capobianco, A.; Borrelli, R.; Landi, A.; Velardo, A.; Peluso, A. Absorption Band Shapes of a Push-Pull Dye Approaching the Cyanine Limit: A Challenging Case for First Principle Calculations. J. Phys. Chem. A 2016, 120, 5581-5589.

(26) Landi, A.; Borrelli, R.; Capobianco, A.; Velardo, A.; Peluso, A. Second-Order Cumulant Approach for the Evaluation of Anisotropic Hole Mobility in Organic Semiconductors. J. Phys. Chem. C 2018, $122,25849-25857$.

(27) Miertuš, S.; Scrocco, E.; Tomasi, J. Electrostatic interaction of a solute with a continuum. A direct utilization of $\mathrm{AB}$ initio molecular potentials for the prevision of solvent effects. Chem. Phys. 1981, 55, 117-129.

(28) Rossotti, F. J. C.; Rossotti, H. S. The Determination of Stability Constants and Other Equilibrium Constants in Solution; McGraw-Hill: New York, 1961.

(29) Gans, P.; Sabatini, A.; Vacca, A. Investigation of equilibria in solution. Determination of equilibrium constants with the HYPERQUAD suite of programs. Talanta 1996, 43, 1739-1753.

(30) SADABS; Bruker-Nonius: Delft, The Netherlands, 2002.

(31) Altomare, A.; Burla, M. C.; Camalli, M.; Cascarano, G. L.; Giacovazzo, C.; Guagliardi, A.; Moliterni, G. G.; Polidori, G.; Spagna, R. SIR97: a new tool for crystal structure determination and refinement. J. Appl. Crystallogr. 1999, 32, 115-119.

(32) Sheldrick, G. M. Crystal structure refinement with SHELXL. Acta Crystallogr., Sect. C: Struct. Chem. 2015, C71, 3-8.

(33) Farrugia, L. J. WinGX and Ortep for Windows: an update. J. Appl. Crystallogr. 2012, 45, 849-854.

(34) Macrae, C. F.; Bruno, I. J.; Chisholm, J. A.; Edgington, P. R.; McCabe, P.; Pidcock, E.; Rodriguez-Monge, L.; Taylor, R.; van de 
Streek, J.; Wood, P. A. Mercury CSD 2.0 - new features for the visualization and investigation of crystal structures. J. Appl. Crystallogr. 2008, 41, 466-470.

(35) NATO standardization agreement (STANAG) on explosives. Impact sensitivity test No. 4489, 1st ed., Sept 17, 1999.

(36) WIWEB-Standardarbeitsanweisung 4-5.1.02. Ermittlung der Explosionsgefährlichkeit, hier der Schlagempfindlichkeit mit dem Fallhammer, Nov 8, 2002.

(37) http://www.bam.de.

(38) NATO standardization agreement (STANAG) on explosive. Friction sensitivity test No. 4487, 1st ed., Aug 22, 2002.

(39) WIWEB-Standardarbeitsanweisung 4-5.1.03. Ermittlung der Explosionsgefährlichkeit oder der Reibeempfindlichkeit mit dem Reibeapparat, Nov 8, 2002.

(40) Impact: insensitive, $>40 \mathrm{~J}$; less sensitive, $\geq 35 \mathrm{~J}$; sensitive, $\geq 4 \mathrm{~J}$; very sensitive, $\leq 3 \mathrm{~J}$. Friction: insensitive, $>360 \mathrm{~N}$; less sensitive, 360 $\mathrm{N}$; sensitive, $<360 \mathrm{~N}$ and $>80 \mathrm{~N}$; very sensitive, $\leq 80 \mathrm{~N}$; extremely sensitive, $\leq 10 \mathrm{~N}$. According to the UN recommendations on the transport of dangerous goods.

(41) http://www.ozm.cz. 